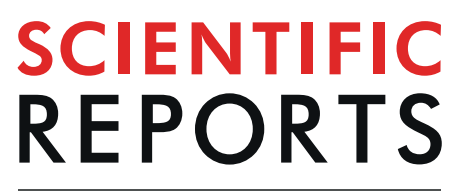

natureresearch

Check for updates

\title{
Leptoria phrygia in Southern Taiwan shuffles and switches symbionts to resist thermal-induced bleaching
}

Ya-Yi Huang ${ }^{1,5}$, Rodrigo Carballo-Bolaños ${ }^{1,2,5}$, Chao-Yang Kuo ${ }^{1}{ }^{1}$, Shashank Keshavmurthy $\mathbb{D}^{1}$ \& Chaolun A. Chen ${ }^{1,2,3,4 凶}$

Symbiodiniaceae communities in some corals often shuffle or switch after severe bleaching events, one of the major threats to coral survival in a world with climate change. In this study we reciprocally transplanted five Leptoria phrygia colonies between two sites with significantly different temperature regimes and monitored them for 12 months. Our ITS2 amplicon deep sequencing demonstrated that $L$. phrygia acclimatized to maintain a strong and stable association with Durusdinium D17, D. trenchii, and $D$. glynnii, but also remained flexible and formed a short-term association with different Cladocopium. Most interestingly, two colonies shuffled between Durusdinium and Cladocopium without the occurrence of bleaching; one colony even switched its dominant Cladocopium after generic shuffling. Both dominant Cladocopium were originally rare with relative abundances as low as $0.024 \%$. This is the first record of adult corals switching dominant symbiont without bleaching.

Stable symbioses between scleractinian corals and dinoflagellate algae (family: Symbiodiniaceae) are key for coral reefs to thrive in tropical oligotrophic waters. More than $90 \%$ of a coral's nutritional requirements are provided by its symbiotic algae ${ }^{1}$. Interruption of such symbioses may force corals to expel their associated algae, which results in coral whitening, a phenomenon best known as bleaching. Temporary bleaching may not kill corals immediately, but recurrent and prolonged bleaching can be fatal ${ }^{2,3}$. Rising sea surface temperatures (SSTs) are one of the major contributors to coral bleaching ${ }^{3}$. Tropical/subtropical SSTs have increased $0.25-0.75^{\circ} \mathrm{C}$ since 1880 due to anthropogenic global warming ${ }^{4}$. Over the past three decades, three mass bleaching events have occurred on a global scale: $1997-1998,2010$, and $2015-17^{4,5}$. The intervals between bleaching events are decreasing and the duration of each event is lengthening. To survive, both corals and their symbiotic algae need to adapt to the rising SSTs.

Coral-associated Symbiodiniaceae currently comprises seven genera and several unnamed but genetically distinct lineages ${ }^{6}$. Two common genera in the Indo-Pacific-Cladocopium (formerly clade C) and Durusdinium (formerly clade D) - are the only Symbiodiniaceae detected in coral colonies from Taiwanese waters ${ }^{7-10}$. Cladocopium is the most diverse genus ${ }^{6,11}$, while members of Durusdinium are known to be resilient to hostile environments, e.g., high temperature or turbidity $\mathrm{y}^{2,6,9,10,12-27}$

In response to rising SSTs, corals and their algal symbionts use different strategies to acclimatize. In some cases, corals expel suboptimal algal species and host more optimal partners ${ }^{28,29}$. Some coral species host different algal symbionts when living in more hostile environments ${ }^{15,23,30-32}$, and some host multiple algal species and adjust the relative abundance of their symbionts, or shuffle between completely different symbionts when necessary ${ }^{9,10,13,27,33-36}$. Most studies have identified the dominant and codominant algal species in corals using conventional Sanger sequencing, restriction fragment length polymorphism (RFLP), quantitative polymerase chain reaction (qPCR), or temperature gradient gel electrophoresis (DGGE). However, these methods have limited resolution and very often fail to detect background species that might be ecologically important but extremely low in quantity (e.g., $<5 \%$ relative abundance) $)^{19,37}$. High-throughput sequencing of the internal transcribed spacer 2 (ITS2) region is a promising approach to better understand intragenomic diversity and differentiate symbionts $^{38,39}$. It can detect rare symbionts with relative abundances $<1 \%$. For example, using this approach, Boulotte et al. ${ }^{40}$ recorded rare symbionts in adult coral colonies and showed that symbiont switching occurred-one colony

${ }^{1}$ Biodiversity Research Center, Academia Sinica, Taipei, Taiwan. ${ }^{2}$ Biodiversity Program, Taiwan International Graduate Program, Academia Sinica; National Taiwan Normal University, Taipei, Taiwan. ${ }^{3}$ Institute of Oceanography, National Taiwan University, Taipei, Taiwan. ${ }^{4}$ Department of Life Science, Tung-Hai University, Taichung, Taiwan. ${ }^{5}$ These authors contributed equally:Ya-Yi Huang and Rodrigo Carballo-Bolaños. ${ }^{凶}$ e-mail: cac@gate.sinica.edu.tw 
became dominated by one of the rare symbionts-after two consecutive bleaching events, a rare phenomenon in adult corals. In this study we applied the same approach to investigate Symbiodiniaceae dynamics in Leptoria phrygia, which is known to host Cladocopium or Durusdinium ${ }^{8,23}$, or both ${ }^{8,41}$, within the same colony.

We tagged and sampled 25 L. phrygia colonies-13 in Wanlitong (WLT) and 12 in the outlet of the third nuclear power plant (OL) in southern Taiwan - to investigate spatial and temporal variation in Symbiodiniaceae communities $^{41}$. We collected five cores from each colony; each core was $10 \sim 20 \mathrm{~cm}$ apart longitudinally and was sampled from the top to the bottom of the colony. Our survey demonstrated that, within individual colonies, there were no correlations between sampling position and the Symbiodiniaceae community; there were, however, positive correlations between the relative abundance of Durusdinium and mean maximum temperature, and between the relative abundance of Durusdinium and temperature variability ${ }^{41}$. Moreover, L. phrygia colonies native to OL were dominated exclusively by Durusdinium glynnii (formerly D1), while those native to WLT were dominated by Cladocopium C3w or C21a, or co-dominated by Cladocopium sp. and D. glynnii ${ }^{41}$. WLT is a sea surface temperature (SST) steady site (SS) with an average summer SST of $29-30^{\circ} \mathrm{C}$ and daily fluctuation of $<3^{\circ} \mathrm{C}^{41}$, while OL is a SST variable site (VS) with an average summer SST of $32-33^{\circ} \mathrm{C}-2-3^{\circ} \mathrm{C}$ higher than any adjacent reef sites ${ }^{10}$-and daily fluctuations up to $10^{\circ} \mathrm{C}^{42}$. Seasonal variation was only observed in colonies co-dominated by both genera; however, despite changes in relative abundance, the dominant species in the colonies remained the same ${ }^{41}$. Background information acquired from this study suggested: (1) L. phrygia can only modify the relative abundance of its symbionts if multiple symbionts exist in the same colony, but dominant symbionts do not change over time. (2) L. phrygia copes with variable environments better by hosting Durusdinium, and only associates with Cladocopium in more stable environments.

The background above begs several questions. Which Symbiodiniaceae are present in individual L. phrygia colonies? Does Symbiodiniaceae composition within the same colony change through time? Can L. phrygia respond to a new habitat completely different from its native one and, if so, how long does it take to adapt? To answer these questions, we narrowed our sampling to 10 colonies, five each randomly selected from the SS and VS. We reciprocally transplanted those colonies and monitored the dynamics of the Symbiodiniaceae community in each for 12 months.

\section{Results}

Transplantation experiment and seawater temperature at the two sites. All deployed nubbins survived the entire experimental period, except the five transplanted Wanlitong (WLT) nubbins of colony V, which died before the first sampling time in July 2015. Therefore, WLT colony V was excluded from subsequent analyses.

The mean monthly temperatures for July 2015, March 2016, and August 2016 were $29.8 \pm 0.4^{\circ} \mathrm{C}, 26.6 \pm 0.7^{\circ} \mathrm{C}$, $24.4 \pm 0.8^{\circ} \mathrm{C}$, and $29.8 \pm 0.5^{\circ} \mathrm{C}$, respectively, in WLT and $29.4 \pm 1.2^{\circ} \mathrm{C}, 27.7 \pm 0.8^{\circ} \mathrm{C}, 25.9 \pm 1.0^{\circ} \mathrm{C}$, and $30.4 \pm 1.1^{\circ} \mathrm{C}$, respectively, in the third nuclear power plant (OL). The Mann-Whitney-Wilcoxon test demonstrated that the mean temperatures were significantly different between two sites for all four months $(\mathrm{p}<0.05)$. It is noteworthy that the mean temperatures in OL were unseasonably low in July 2015, possibly due to a super typhoon passing by southern Taiwan and reducing the mean summer temperature in OL.

Sequencing and BLAST search results. The total number of reads in each library ranged from 4,527,909 to $6,123,654$, and were reduced to $4,524,407$ and $6,119,645$ after quality trimming. The average read lengths were 274.1 to 284.5 bp (Table S1). Paired-read merging produced 9,795,746 assembled reads. After replicates were removed, 511,458 unique OTUs remained (56 nubbins in total). BLAST search against Symbiodiniaceae ITS2 references identified 80,236 sequences qualified for downstream analysis. Initial analysis revealed that $87.4 \%$ of those sequences belonged to Durusdinium and only $12.6 \%$ belonged to Cladocopium. Within individual nubbins, the first sampling in July 2015 showed that all nubbins, including native (control) and transplanted ones from both sites, exhibited an extremely high ratio of Durusdinium to Cladocopium (92 99\%, Fig. 1).

Relative abundance analysis demonstrated that, in native WLT colonies, ratios of Durusdinium to Cladocopium were highest ( $\geq 90 \%$ ) in summer (July 2015 and August 2016), when the SST was the highest (ca. $29.8^{\circ} \mathrm{C}$ ). In fall-winter (November 2015) and spring (March 2016), when the SST was cooler (ca. 26.6 and $24.4^{\circ} \mathrm{C}$, respectively), the Durusdinium to Cladocopium ratios decreased slightly in colonies I, II, and IV. In colony III, however, the Durusdinium to Cladocopium ratio decreased dramatically to as low as 6\%, while the Cladocopium to Durusdinium ratio increased to 94\%, becoming the dominant Symbiodiniaceae genus in November (Fig. 1). The Cladocopium-dominant stage lasted until March, but the Cladocopium to Durusdinium ratio decreased to $65 \%$, then to $9 \%$ in August, at which time Durusdinium increased to $91 \%$ and regained dominance (Fig. 1). In OL, ratios of Durusdinium to Cladocopium were mostly $>90 \%$ for every month, except in colonies III and V, which had a Durusdinium to Cladocopium ratio of $72 \%$ in March and $81 \%$ in August 2016 (Fig. 1). In transplanted WLT colonies, the Durusdinium to Cladocopium ratios were all $>90 \%$, without seasonal variations. In transplanted OL colonies, the Durusdinium to Cladocopium ratios remained high (>80\%), without seasonal variation, except in colony V, which had no summer samples but did have a Durusdinium to Cladocopium ratio as low as 6 and 14\% in November 2015 and March 2016, respectively.

The chi-squared tests indicated that the relative abundances of Durusdinium and Cladocopium were significantly $(\mathrm{p}<0.05)$ or highly significantly $(\mathrm{p}<0.001)$ different $($ Table 1$)$ between native and transplanted samples in all WLT samples, regardless of the colony or season. In colonies I and II of the OL samples, the relative abundances of Durusdinium and Cladocopium between native and transplanted samples were not significantly different in November, but were in March and August. For colony III, the difference was highly statistically significant $(\mathrm{p}<0.001)$ at all sampling times (Table 1). It was not different for colony IV, but was highly significantly different for colony $\mathrm{V}$ (Table 1$)$. 
WLT (SS)

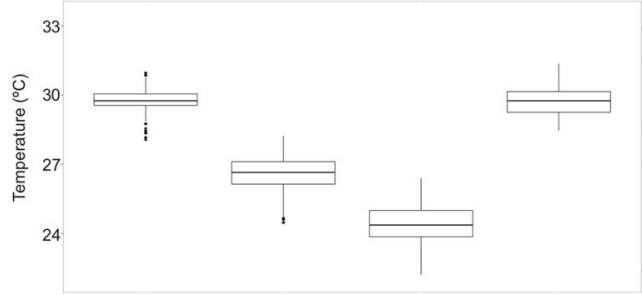

WLT Native (SS)

Colony I
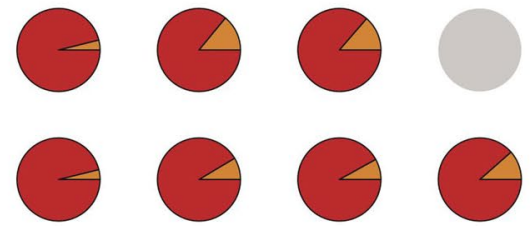

Colony III
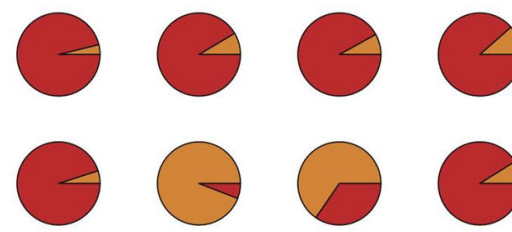

Colony IV
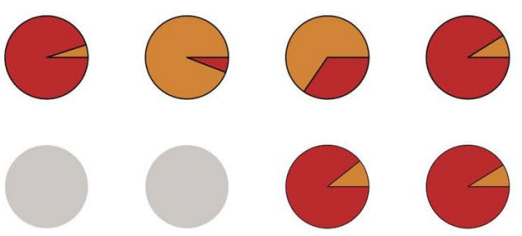

OL Transplanted (SS)
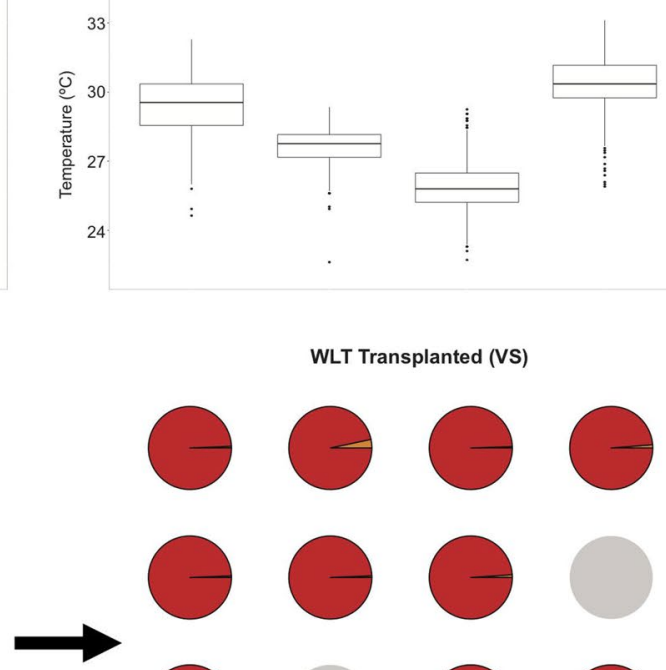

WLT Transplanted (VS)
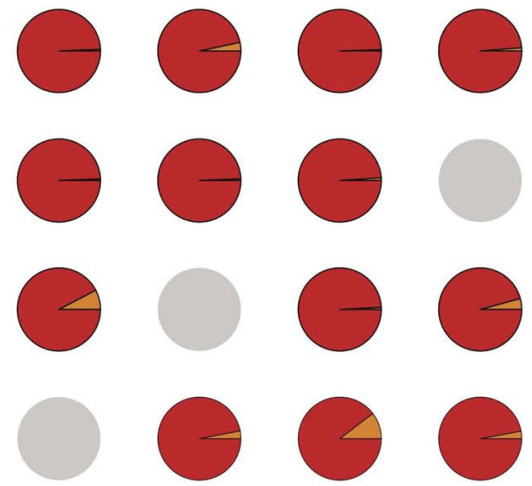

OL Native (VS)

Colony
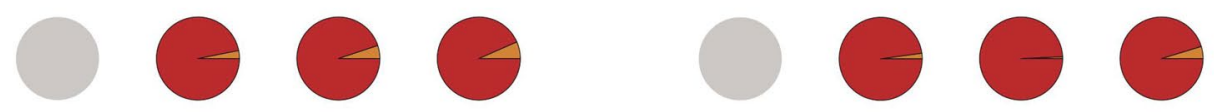

Colony II
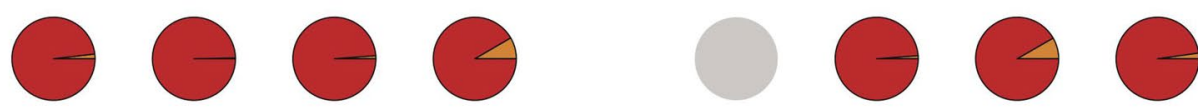

Colony III
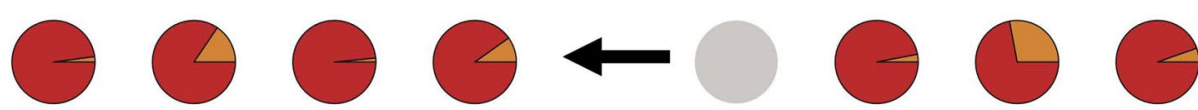

Colony IV
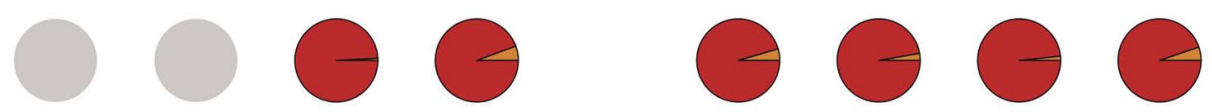

Colony $\mathrm{V}$
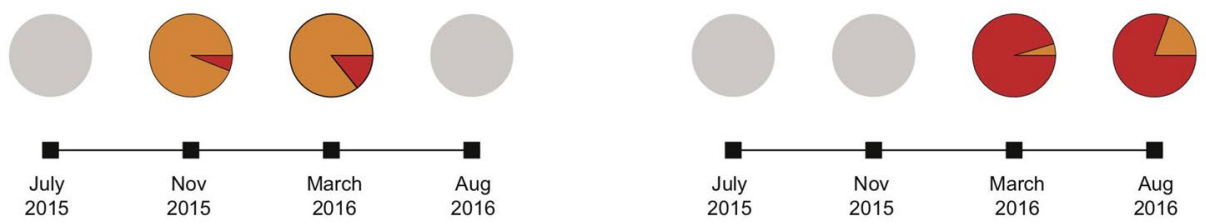

Cladocopium

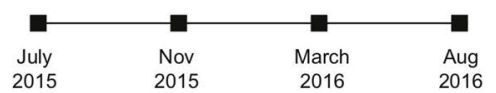

Figure 1. Temperature of four sampling months and seasonal dynamics of Durusdinium and Cladocopium.

Composition and dynamics of dominant ITS2 sequences. Symbiodiniaceae profiling demonstrated that both Durusdinium and Cladocopium were present within every individual L. phrygia nubbin. In most of the cases, the relative abundance of the top five taxa accounted for over $80 \%$ of the total ITS2 sequences within individual samples; therefore, only the relative abundances of the top five were listed, and the rest were pooled and classified as "Others." Regardless of the site or season, L. phrygia colonies can be defined as having Durusdiniumand Cladocopium-dominant stages. During the Durusdinium-dominant stage, the relative abundance of the top three were always Durusdinium D17, D. trenchii (D1a), and D. glynnii (D1) (Figs. 2-3). Moreover, the relative abundance of the three occupied $65 \sim 95 \%$ of all Symbiodiniaceae in each colony.

During the Cladocopium-dominant stage, however, the relative abundances of the top three were more variable. For example, in WLT colony III, the top three most abundant taxa changed from Cladocopium C3s, C50, and C3b in November 2015 to C50, D17, and C3s in March 2016 (Fig. 2). In OL-transplanted colony V, the top three 


\begin{tabular}{|c|c|c|c|c|c|c|c|c|c|}
\hline \multirow[b]{2}{*}{ WLT } & \multicolumn{2}{|l|}{2015} & \multicolumn{2}{|l|}{2016} & \multirow[b]{2}{*}{ OL } & \multicolumn{2}{|c|}{2015} & \multicolumn{2}{|l|}{2016} \\
\hline & July & November & March & August & & July & November & March & August \\
\hline colony I & $<0.001 * *$ & $<0.001 * *$ & $<0.001 * *$ & - & colony I & - & 0.2042 & $<0.001$ ** & $<0.05^{*}$ \\
\hline colony II & $<0.001 * *$ & $<0.001 * *$ & $<0.001 * *$ & - & colony II & - & 0.0313 & $<0.001 * *$ & $<0.001 * *$ \\
\hline colony III & $<0.001$ ** & - & $<0.001 * *$ & $<0.001 * *$ & colony III & - & $<0.001 * *$ & $<0.001 * *$ & $<0.001 * *$ \\
\hline colony IV & - & - & $<0.05^{*}$ & $<0.001 * *$ & colony IV & - & - & 0.1111 & 0.5787 \\
\hline colony V & - & - & - & - & colony V & - & - & $<0.001 * *$ & - \\
\hline
\end{tabular}

Table 1. Chi-squared tests for the differences in relative abundances of Durusdinium and Cladocopium between native (control) and transplanted samples of each colony. "- " means that a pair-wise test was not available due to missing samples; “*” denotes statistically significant and “**” denotes highly statistically significant.

most abundant symbionts in November and March were C21a, C3s, and C3d (Fig. 3). Seasonal tracking of C3s and C50 in WLT colony III showed that the relative abundance of the two were as low as $0.24 \%$ in July, when the SST was the highest (ca. $29.8^{\circ} \mathrm{C}$ ) and the colony was dominated by Durusdinium. However, in November 2015, when the SST decreased to ca. $26.6^{\circ} \mathrm{C}$, the relative abundance of $\mathrm{C} 3 \mathrm{~s}$ increased to $21.5 \%$ and became the most abundant symbiont (Fig. 2). In March 2016, the highest relative abundance switched from C3s to C50 (which increased to $22.68 \%$ ) when the SST further decreased to $24.4^{\circ} \mathrm{C}$. In August 2016, when the SST increased to $>29^{\circ} \mathrm{C}$ again, the relative abundance of both C3s and C50 decreased to $<1 \%$ (Fig. 4 ) and the colony became dominated by Durusdinium again (Fig. 2). A combined analysis of all colonies from both sites searching for rare symbionts (relative abundances of the top five were excluded) also demonstrated an interesting trend: relative abundances of rare Cladocopium were low in July and August, when the SST was the highest. When the SST decreased in November, the relative abundance of rare Cladocopium increased (Fig. 5). However, when the SST further decreased in March, the relative abundance of Cladocopium also decreased. In addition, new Cladocopium ITS2 sequences appeared in each sampling month, showing peak diversities in November (11 total) and March (9 total). However, those sequences were transient, and none survived to the next sampling month (Fig. 5).

\section{Discussion}

Our study demonstrated that ITS2 sequences in L. phrygia comprise few Durusdinium and numerous background Cladocopium. For the first sampling (July 2015), all colonies at both sites were particularly dominated by Durusdinium (relative abundance $>90 \%$ ). Our results concur with those of Carballo-Bolaños et al. ${ }^{41}$ in that colonies able to adjust their relative abundances of Durusdinium and Cladocopium mostly retained the same dominant symbiont through time; there were two exceptions: (1) native WLT colony III and transplanted third nuclear power plant (OL) colony V both shuffled from Durusdinium- to Cladocopium-dominated in November 2015 and March 2016, when the SST decreased (Fig. 1), and (2) native WLT colony III shuffled to become Durusdinium-dominant again when the SST increased again in August 2016 (Fig. 1). Instead of the D. glynnii and C3w or C21a recognized in Carballo-Bolaños et al. ${ }^{41}$, dominant symbionts in this study were D17 and C3s, C50, or C21a (Figs. 2-3).

Moreover, our Symbiodiniaceae profiling demonstrated that, for colonies dominated by Durusdinium, the top three most dominant symbionts were always D17, D. trenchii, and D. glynnii, and together they constituted more than $65 \%$ (majority $>90 \%$ ) of the Symbiodiniaceae. In contrast, Cladocopium-dominated colonies depended on the accumulation of different Cladocopium, each with a low relative abundance; even the most abundant taxon made up only ca. 21 22\% (C3s and C50 in Fig. 2) or 34\% (C21a in Fig. 3) of all Symbiodiniaceae. Most interestingly, in addition to dominant genus shuffling after the SST decreased in November $\left(26.6^{\circ} \mathrm{C}\right)$, we also recorded a switch in dominant Cladocopium-i.e., C3s to C50 in WLT colony III when the SST decreased two more degrees $\left(24.4^{\circ} \mathrm{C}\right)$ in March. Based on the results above, we can infer that L. phrygia has acclimatized to maintain a strong and stable association with three Durusdinium - D17, D. trenchii, and D. glynnii-but remained flexible enough to form a short-term association with Cladocopium.

Hosting a great quantity of Durusdinium, however, comes at a cost. Durusdinium is known as an opportunist that seizes the chance to become dominant in corals facing adverse conditions, and Durusdinium dominancy often has negative effects on coral health ${ }^{26,43}$. However, for corals living on the edge-e.g., the VS in our studyretaining considerable quantities of Durusdinium seems unavoidable. Our transplantation experiment validated the advantages of associating with Durusdinium when environmental conditions deteriorate: one colony died and the four surviving colonies all hosted Durusdinium exclusively (ca. $97 \%$ on average) after they were transplanted from the SS to VS. On the other hand, four of the five OL colonies remained Durusdinium-dominant, and the last one shuffled to become Cladocopium-dominant after transplantation from the VS (OL) to SS (WLT).

The evidence above suggests that the Durusdinium to Cladocopium ratio was so high $(>92 \%)$ in all colonies in July due to the high SST combined with stress resulting from relocation, indicating aggravating ambient conditions. Although L. phrygia was able to shuffle to Cladocopium when the environment was less adverse-e.g., SST decreased-even switching to different dominant Cladocopium, the association with Cladocopium was only temporary. As soon as the SST increased again the next summer, the colony shuffled back to the same top three Durusdinium. Our results concur with another study on three coral species (Pocillopora acuta, Acropora cytherea, and Porites rus) that possess a unique Symbiodiniaceae signature: a suite of permanent Symbiodiniaceae genera in each colony ${ }^{44}$.

Previous studies show that corals do not take up algal symbionts indiscriminately ${ }^{45}$, nor do they change their dominant algal genus easily ${ }^{46}$. Moreover, before NGS techniques, the uptake of novel symbionts was only reported 


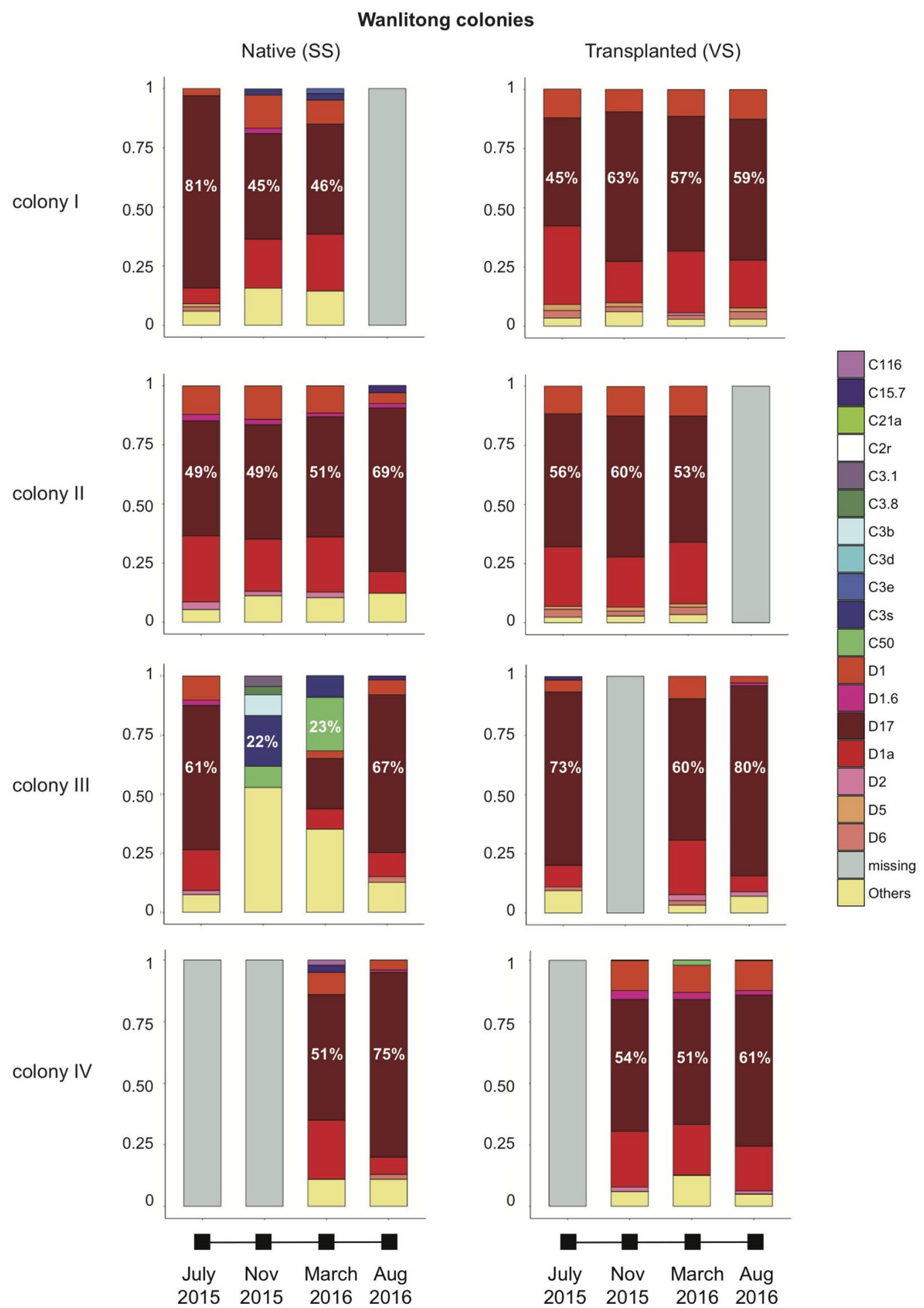

Figure 2. Top five symbionts in WLT colonies. Symbionts other than top five were pooled and defined as Others. Percentages of the most dominant symbionts are labeled.

in corals at the juvenile stage, when the association was non-specific and flexible ${ }^{47,48}$. Even today, novel symbiont acquisition and switching in adult corals has only been reported in one case study-on Pocillopora damicornis after two consecutive bleaching events ${ }^{40}$. Our study is unique in that we monitored individual colonies and recorded the shuffling between Durusdinium and Cladocopium, as well as between dominant Cladocopium that switched within one particular colony over a period as short as 12 months without bleaching. This is the first record of a dominant symbiont switch in adult corals not triggered by bleaching.

However, although the uptake of novel symbionts by adult corals was reported in both Boulotte et al..$^{40}$ (driven by bleaching) and our study (not driven by bleaching), whether or not the two cases truly constitute a switch 


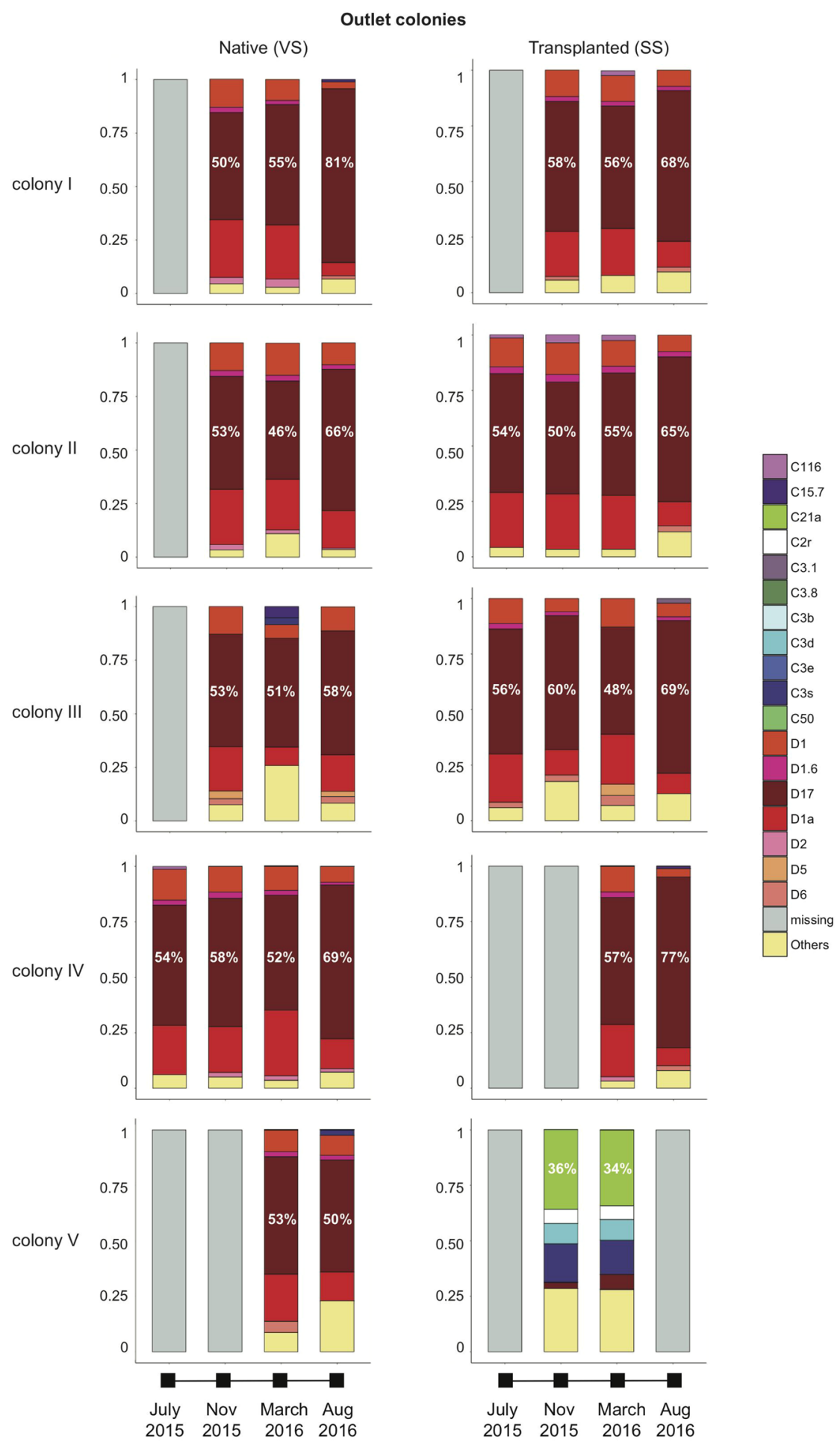

Figure 3. Top five symbionts in OL colonies. Symbionts other than top five were pooled and defined as Others. Percentages of the most dominant symbionts are labeled.

is still equivocal. By definition, switching involves acquiring novel symbionts from the environment that later increase in abundance and dominate the colony ${ }^{40,49}$. The symbionts in these studies that switched actually existed in the colony before they were taken up, although their relative abundance was extremely low- $0.03 \%$ in Boulotte et $a .^{40}$ and $0.024 \%$ in our study. Nonetheless, we did detect new symbionts for each sampling month, but they never survived to the next sampling.

In conclusion, our study elucidated that L. phrygia has acclimatized to associate with three particular Durusdinium (D17, D. trenchii, and D. glynnii), but keeps numerous background Cladocopium in stock that may increase in abundance to dominate the colony when ambient conditions are less adverse. Sequences of new 


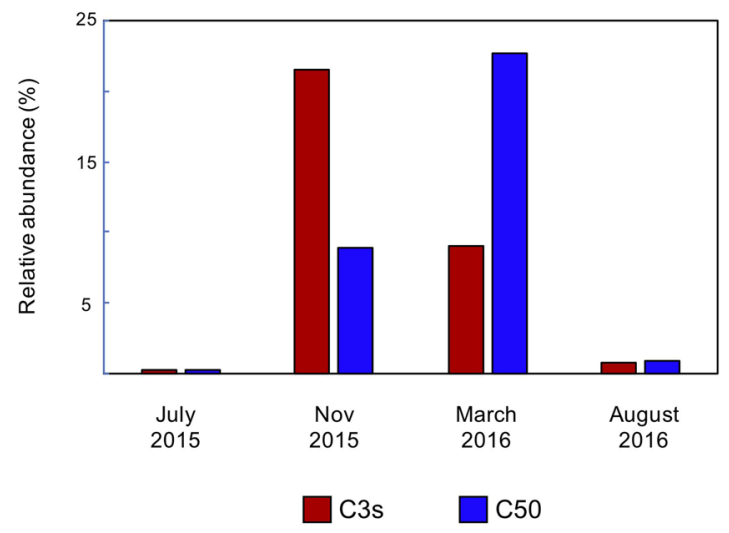

Figure 4. Switching in the most dominant Cladocopium in WLT colony III.

taxa are sporadically acquired from the environment, but they are transient and do not survive long enough to increase much in abundance. Consequently, L. phrygia may stand a chance of resisting recurrent and prolonged bleaching by solidly associating with Durusdinium supplemented with sporadic shuffling between Durusdinium and background Cladocopium. This coral is also resilient and recovers quickly from bleaching due to its swift responses to changing environments.

\section{Methods}

Sampling, temperature monitoring, DNA extraction, amplicon amplification, and sequencing. The study was conducted in Kenting National Park, southern Taiwan. We received a field permit (number: 1040008112) to conduct a reciprocal transplant experiment (spanning four seasons over 1 year) between Wanlitong (WLT) and the outlet of the third nuclear power plant (OL). The permit allowed us to sample 10 colonies from the two sites (WLT: 5 colonies, OL: 5 colonies) and collect a maximum of 10 subsamples from each colony, which was sufficient for our experimental design ( 80 samples in total for $\mathrm{N}=5$ per season/per site). Five L. phrygia colonies at 3-5 $\mathrm{m}$ deep from OL $\left(21^{\circ} 55^{\prime} 53.7^{\prime \prime} \mathrm{N}-120^{\circ} 44^{\prime} 42.7^{\prime \prime} \mathrm{E}\right)$ and five colonies at 3-5 $\mathrm{m}$ deep from WLT $\left(21^{\circ} 59^{\prime} 43.9^{\prime \prime} \mathrm{N}-120^{\circ} 42^{\prime} 23.2^{\prime \prime} \mathrm{E}\right)$ were haphazardly selected for subsample coring in March 2015. Sampled colonies were separated by at least $7-10 \mathrm{~m}$ to avoid sampling clones.

Procedures for coring and nubbin production were modified from Kao et al. ${ }^{50}$. Briefly, 10 cores $(2.5 \mathrm{~cm}$ in diameter) were taken from each colony using a set of underwater drills. To reduce sampling effect, all cores were brought back to the laboratory in the National Museum of Marine Biology and Aquarium for processing and acclimatizing. In the laboratory, individual cores were attached to PVC tubes with epoxy (nubbins). Fifty nubbins collected from the same site were equally distributed on two fiberglass racks ( 25 nubbins each). On each rack, five nubbins from the same colony were arranged on the same row. Four racks (100 nubbins) were acclimatized for 96 hours and then returned to their native sites: two racks with WLT nubbins back to WLT and two racks with OL nubbins back to OL. The racks were fixed to the reefs at a depth of 3-5 $\mathrm{m}$ and allowed to acclimate for four weeks. In April 2015, one of the racks from each site was reciprocally transplanted to the other site, i.e., one WLT rack was transplanted to $\mathrm{OL}$ and vice versa. The other rack remained at the native site as the experimental control.

Data loggers (HOBO Pendant 64 K, USA) deployed at $3 \mathrm{~m}$ deep recorded ambient SST hourly from April 2015 to August 2016. Seasonal variation in the Symbiodiniaceae community compositions of native and transplanted nubbins were examined by collecting one nubbin per colony every three to four months. Nubbins were sampled in July 2015 (summer), November 2015 (fall-winter), March 2016 (spring), and August 2016 (summer). A total of 80 nubbins were collected from the racks by scuba diving, but some were lost during the sampling process. Consequently, fewer than 80 nubbins were brought back to the laboratory for molecular study. In the laboratory, a small piece of coral tissue was collected from each nubbin and fixed in $100 \%$ ethanol for DNA extraction using a modified high salt protocol ${ }^{51}$. Briefly, about $30 \mathrm{mg}$ of coral tissue ( 3-4 polyps) was fragmented and incubated at $55-60^{\circ} \mathrm{C}$ overnight in a $200-\mu \mathrm{l}$ lysis buffer mixture (recipes for $100 \mathrm{ml}$ solution were: $1 \mathrm{M}$ Tris-Boric $25 \mathrm{ml}, 0.5$ EDTA pH $\left.810 \mathrm{ml}, 20 \% \mathrm{SDS} 10 \mathrm{ml}, 5 \mathrm{M} \mathrm{NaCl} 2 \mathrm{ml}, \mathrm{ddH}_{2} \mathrm{O} 53 \mathrm{ml}\right)$ and pronase $\mathrm{E}(10 \mu \mathrm{l}$ at $10 \mathrm{mg} / \mathrm{ml})$. To precipitate the DNA, $210 \mu \mathrm{l} \mathrm{NaCl}(7 \mathrm{M})$ was added to the lysis solution and mixed by inverting the tubes several times. The mixture was centrifuged at $10,000 \times \mathrm{g}$ for $30 \mathrm{~min}$. The resulting supernatant was transferred into a new tube, mixed with $100 \%$ isopropanol $(420 \mu \mathrm{l})$ for $5 \mathrm{~min}$, and incubated at $-20^{\circ} \mathrm{C}$ for at least two hours. To clean the DNA, samples were centrifuged for $30 \mathrm{~min}$ at $16,000 \times \mathrm{g}$ and the supernatant was discarded. The DNA pellet was rinsed with $70 \%$ cold ethanol $(150 \mu \mathrm{l})$ three times and dried in a laminar hood for $1-2 \mathrm{hr}$. A total volume of $150 \mu \mathrm{l}$ preheated $\left(65^{\circ} \mathrm{C}\right)$ TE buffer $(1 \times)$ was added to elute the DNA.

The primers ITSintfor $2\left(5^{\prime}\right.$-GAATTGCAGAACTCCGTG - $\left.3^{\prime}\right)$ and ITS2 (5'-GGGATCCATATGCTTAAGTTC AGCGGGT $-3^{\prime}$ ) were used to amplify the ITS2 spacer along with partial ribosomal RNA genes ( $5.8 \mathrm{~S}$ and $28 \mathrm{~S}$ ). Sixteen unique barcodes (6-bp) were attached to the 5' end of the forward primer (ITSinfor2) for Illumina multiplex sequencing. Taq DNA polymerase RED (Ampliqon) was used for PCR amplification using the following conditions: initial denaturation at $95^{\circ} \mathrm{C}$ for $5 \mathrm{~min}$, followed by 35 cycles at $95^{\circ} \mathrm{C}$ for $30 \mathrm{~s}, 53 \sim 55^{\circ} \mathrm{C}$ for $30 \mathrm{~s}, 72^{\circ} \mathrm{C}$ for $30 \mathrm{~s}$, and a final extension at $72^{\circ} \mathrm{C}$ for $10 \mathrm{~min}$. The resulting amplicons were purified using the Gel/PCR DNA Purification Mini Kit (NovelGene, Taiwan) and measured with Nanodrop to determine the concentration and 
A

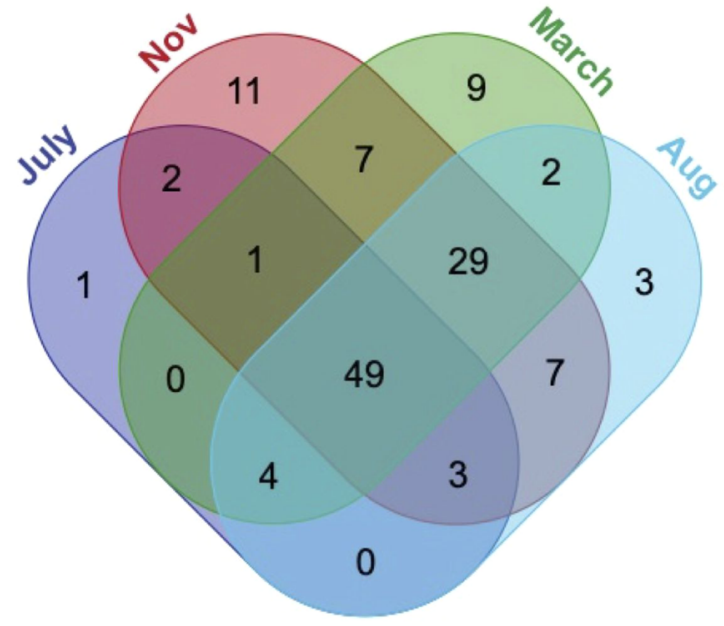

B

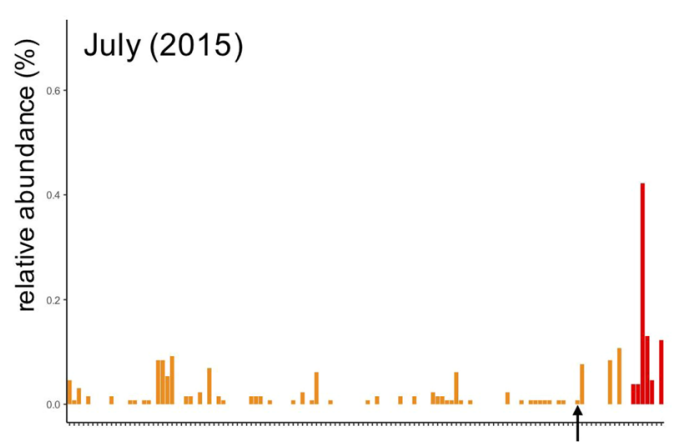

Species

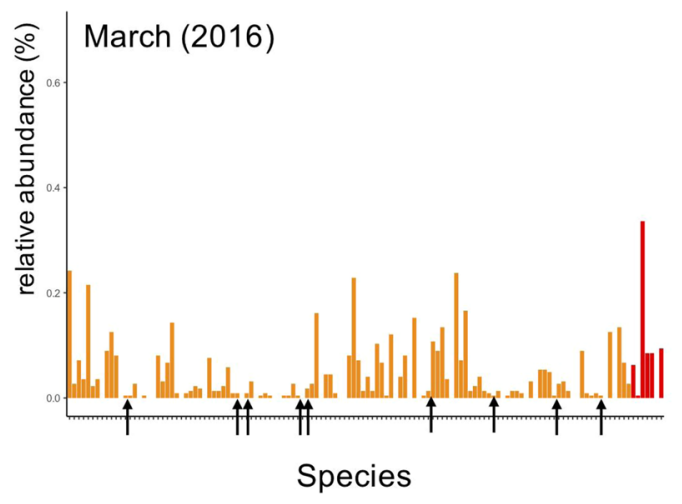

Cladocopium

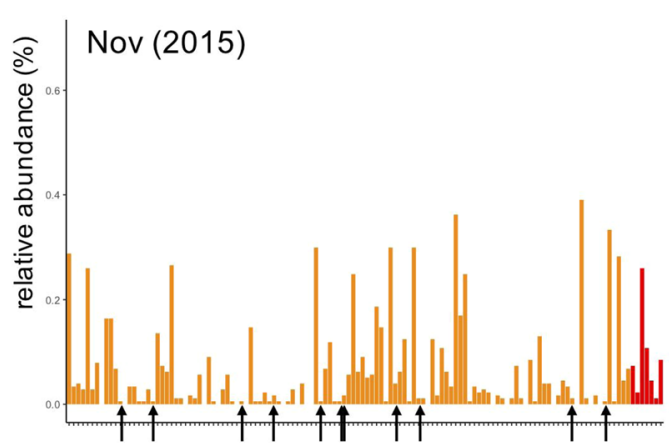

Species

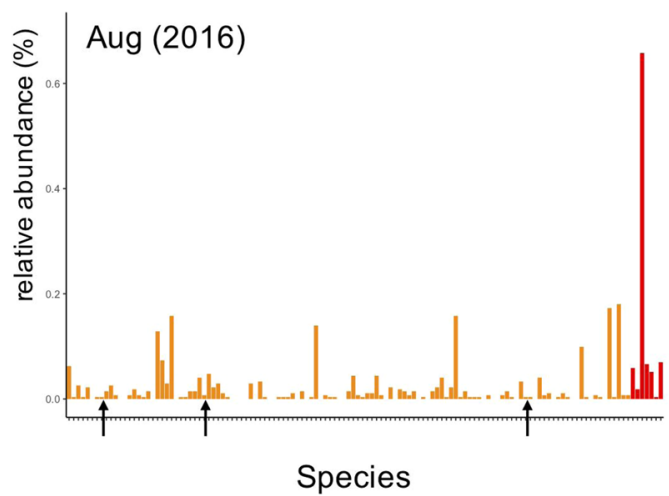

Durusdinium

Figure 5. Analysis of rare symbionts. (A) Venn diagram of shared and unique symbionts among sampling months. (B) Distribution of rare symbionts in each month. X axis displays 128 other than the top five symbionts. Black arrows denote unique symbionts that only appeared in that sampling month.

purity. A total of five tubes were prepared and delivered to Yourgene Bioscience, Co. (New Taipei City, Taiwan) for library construction and amplicon sequencing using Illumina MiSeq, $2 \times 300$ bp paired-end (MiSeq Reagent kit v3, Illumina Inc., CA, USA). Each tube contained 16 samples that could be distinguished by the unique barcode attached to the 5 ' end of the forward primer.

Data processing, ITS2 database establishment, and data analysis. Initial read trimming (error probability $<0.05$ ); barcode sorting; and adaptor, primer, and barcode removal were performed by Yourgene Bioscience, Co. (New Taipei City, Taiwan). Read lengths shorter than $35 \mathrm{bp}$ and unpaired reads were removed from downstream analyses. Paired forward and reverse reads were further trimmed (PHRED quality score $=$ 
33, quality score threshold $=30$ ) and then merged using PEAR v0.9.10 ${ }^{52}$. For each sample, the merged reads were imported independently into QIIME ${ }^{53}$ for operational taxonomic unit (OTU) selection using the UCLUST method and a $97 \%$ similarity threshold. A previous study demonstrated that $97 \%$ within sample clustering collapses intragenomic sequences and only preserves sequences that are most likely interspecific ${ }^{54}$. The most abundant sequence variant in each $97 \%$ cluster was selected as the representative OTU. Only representative OTUs were used in downstream analyses. The identity of each representative OTU was determined by BLAST search against reference sequences from Arif et al. ${ }^{38}$ and Tong et al..$^{55}$ with an e-value threshold of $10^{-5}$. The output with length coverage $<250$ bp or identity $<97 \%$ were removed from further analyses. The relative abundances of Cladocopium and Durusdinium were calculated by the equation: total Cladocopium OTUs or total Durusdinium OTUs divided by total OTUs. All raw reads were deposited into GenBank and will be accessible once this manuscript is published (accession number PRJNA580156).

Statistical analyses. Mean monthly temperature was calculated for each site, and the differences between the two sites over four sampling months were determined by non-parametric Mann-Whitney-Wilcoxon test. Differences in relative abundance between native and transplanted samples of each colony were evaluated by chi-squared tests. All statistical analyses were performed in $\mathrm{R}$ (version 3.4.2). Shared and unique symbionts across seasons were calculated through the Bioinformatics \& Evolutionary Genomics online server (http://bioinformatics.psb.ugent.be/webtools/Venn/).

Received: 11 December 2019; Accepted: 16 April 2020;

Published online: 08 May 2020

\section{References}

1. Muscatine, L. In Ecosystems of the world 25: Coral reefs (ed. Z. Dubinsky) 75-84 (Elsevier (1990).

2. Glynn, P. W., Maté, J. L., Baker, A. C. \& Calderón, M. O. Coral bleaching and mortality in Panama and Ecuador during the 1997-1998 El Niño-Southern Oscillation Event: spatial/temporal patterns and comparisons with the 1982-1983 event. Bull. Mar. Sci. 69, 79-109 (2001).

3. Glynn, P. W. Coral reef bleaching: facts, hypotheses and implications. Glob. Change Biol. 2, 495-509, https://doi. org/10.1111/j.1365-2486.1996.tb00063.x (1996).

4. Hughes, T. P. et al. Coral reefs in the Anthropocene. Nature 546, 82, https://doi.org/10.1038/nature22901 https://www.nature.com/ articles/nature22901\#supplementary-information (2017).

5. Hughes, T. P. et al. Spatial and temporal patterns of mass bleaching of corals in the Anthropocene. Science 359, 80, https://doi. org/10.1126/science.aan8048 (2018).

6. LaJeunesse, T. C. et al. Systematic revision of Symbiodiniaceae highlights the antiquity and diversity of coral endosymbionts. Curr. Biol. 28, 2570-2580.e2576, https://doi.org/10.1016/j.cub.2018.07.008 (2018).

7. Chen, C. A., Yang, Y.-W., Wei, N. V., Tsai, W.-S. \& Fang, L.-S. Symbiont diversity in scleractinian corals from tropical reefs and subtropical non-reef communities in Taiwan. Coral Reefs 24, 11-22, https://doi.org/10.1007/s00338-004-0389-7 (2005).

8. Keshavmurthy, S. et al. Can resistant coral-Symbiodinium associations enable coral communities to survive climate change? A study of a site exposed to long-term hot water input. PeerJ 2, e327, https://doi.org/10.7717/peerj.327 (2014).

9. Hsu, C.-M. et al. Temporal and spatial variations in symbiont communities of catch bowl coral Isopora palifera (Scleractinia: Acroporidae) on reefs in Kenting National Park, Taiwan. Zool. Stud. 51, 1343-1353 (2012).

10. Keshavmurthy, S. et al. Symbiont communities and host genetic structure of the brain coral Platygyra verweyi, at the outlet of a nuclear power plant and adjacent areas. Mol. Ecol. 21, 4393-4407, https://doi.org/10.1111/j.1365-294X.2012.05704.x (2012).

11. Baker, A. C. Flexibility and specificity in coral-algal symbiosis: diversity, ecology, and biogeography of Symbiodinium. Annual Review of Ecology 34, https://doi.org/10.1146/annurev.ecolsys.34.011802.132417 (2003).

12. Fabricius, K. E., Mieog, J. C., Colin, P. L., Idip, D. \& van Oppen, M. J. H. Identity and diversity of coral endosymbionts (zooxanthellae) from three Palauan reefs with contrasting bleaching, temperature and shading histories. Mol Ecol 13, https://doi. org/10.1111/j.1365-294X.2004.02230.x (2004).

13. Cunning, R., Silverstein, R. N. \& Baker, A. C. Symbiont shuffling linked to differential photochemical dynamics of Symbiodinium in three Caribbean reef corals. Coral Reefs 37, 145-152, https://doi.org/10.1007/s00338-017-1640-3 (2018).

14. LaJeunesse, T. C. et al. Long-standing environmental conditions, geographic isolation and host-symbiont specificity influence the relative ecological dominance and genetic diversification of coral endosymbionts in the genus. Symbiodinium. J. Biogeogr. 37, 785-800, https://doi.org/10.1111/j.1365-2699.2010.02273.x (2010).

15. Rowan, R. Coral bleaching: thermal adaptation in reef coral symbionts. Nature 430, https://doi.org/10.1038/430742a (2004).

16. Garren, M., Walsh, S. M., Caccone, A. \& Knowlton, N. Patterns of association between Symbiodinium and members of the Montastraea annularis species complex on spatial scales ranging from within colonies to between geographic regions. Coral Reefs 25, 503-512, https://doi.org/10.1007/s00338-006-0146-1 (2006).

17. Lien, Y.-T. et al. Occurrence of the putatively heat-tolerant Symbiodinium phylotype D in high-latitudinal outlying coral communities. Coral Reefs 26, 35-44, https://doi.org/10.1007/s00338-006-0185-7 (2007).

18. Ghavam Mostafavi, P., Fatemi, S. M. R., Shahhosseiny, M. H., Hoegh-Guldberg, O. \& Loh, W. K. W. Predominance of clade D Symbiodinium in shallow-water reef-building corals off Kish and Larak Islands (Persian Gulf, Iran). Mar. Biol. 153, 25-34, https:// doi.org/10.1007/s00227-007-0796-8 (2007).

19. LaJeunesse, T. C. et al. Specificity and stability in high latitude eastern Pacific coral-algal symbioses. Limnology Oceanography 53, 719-727, https://doi.org/10.4319/lo.2008.53.2.0719 (2008)

20. Tonk, L., Sampayo, E. M., Weeks, S., Magno-Canto, M. \& Hoegh-Guldberg, O. Host-specific interactions with environmental factors shape the distribution of Symbiodinium across the Great Barrier Reef. Plos One 8, e68533, https://doi.org/10.1371/journal. pone.0068533 (2013).

21. Hennige, S. J. et al. Acclimation and adaptation of scleractinian coral communities along environmental gradients within an Indonesian reef system. J. Exp. Mar. Biol. Ecol. 391, 143-152, https://doi.org/10.1016/j.jembe.2010.06.019 (2010).

22. Lien, Y.-T. et al. Host genetics and Symbiodinium D diversity in a stress-tolerant scleractinian coral, Oulastrea crispata, in the West Pacific. Mar. Ecol. Prog. Ser. 473, 163-177 (2013).

23. Oliver, T. A. \& Palumbi, S. R. Many corals host thermally resistant symbionts in high-temperature habitat. Coral Reefs 30, 241-250, https://doi.org/10.1007/s00338-010-0696-0 (2011).

24. Hume, B. C. C. et al. Symbiodinium thermophilum sp. nov., a thermotolerant symbiotic alga prevalent in corals of the world's hottest sea, the Persian/Arabian Gulf. Scientific Reports 5, 8562, https://doi.org/10.1038/srep08562 https://www.nature.com/articles/ srep08562\#supplementary-information (2015). 
25. Stat, M. et al. The distribution of the thermally tolerant symbiont lineage (Symbiodinium clade D) in corals from Hawaii: correlations with host and the history of ocean thermal stress. Ecol. Evol. 3, 1317-1329, https://doi.org/10.1002/ece3.556 (2013).

26. Silverstein, R. N., Cunning, R., Baker, A. C. \& Tenacious, D. Symbiodiniumin clade D remain in reef corals at both high and low temperature extremes despite impairment. J Exp Biol 220, https://doi.org/10.1242/jeb.148239 (2017).

27. Kemp, D. W., Hernandez-Pech, X., Iglesias-Prieto, R., Fitt, W. K. \& Schmidt, G. W. Community dynamics and physiology of Symbiodinium spp. before, during, and after a coral bleaching event. Limnology Oceanography 59, 788-797, https://doi.org/10.4319/ lo.2014.59.3.0788 (2014).

28. Baker, A. C. Reef corals bleach to survive change. Nature 411, 765, https://doi.org/10.1038/35081151 (2001).

29. Silverstein, R. N., Cunning R Fau-Baker, A. C. \& Baker, A. C. Change in algal symbiont communities after bleaching, not prior heat exposure, increases heat tolerance of reef corals. Glob. Change Biol. 21, 236-249 (2015).

30. Rowan, R., Knowlton, N., Baker, A. \& Jara, J. Landscape ecology of algal symbionts creates variation in episodes of coral bleaching. Nature 388, 265, https://doi.org/10.1038/40843 (1997).

31. Baker, A. C., Starger, C. J., McClanahan, T. R. \& Glynn, P. W. Corals' adaptive response to climate change. Nature 430, 741, https:// doi.org/10.1038/430741a https://www.nature.com/articles/430741a\#supplementary-information (2004).

32. Császár, N. B. M., Ralph, P. J., Frankham, R., Berkelmans, R. \& van Oppen, M. J. H. Estimating the potential for adaptation of corals to climate warming. Plos One 5, e9751, https://doi.org/10.1371/journal.pone.0009751 (2010).

33. Cunning, R., Silverstein, R. N. \& Baker, A. C. Investigating the causes and consequences of symbiont shuffling in a multi-partner reef coral symbiosis under environmental change. Proc. R. Soc. B 282, 20141725, https://doi.org/10.1098/rspb.2014.1725 (2015).

34. Lewis, C., Neely, K. \& Rodriguez-Lanetty, M. Recurring episodes of thermal stress shift the balance from a dominant host-specialist to a background host-generalist Zooxanthella in the threatened pillar coral, Dendrogyra cylindrus. Frontiers in Marine Science 6 , https://doi.org/10.3389/fmars.2019.00005 (2019).

35. Chen, C. A., Wang, J.-T., Fang, L.-S. \& Yang, Y.-W. Fluctuating algal symbiont communities in Acropora palifera (Scleractinia: Acroporidae) from Taiwan. Mar. Ecol. Prog. Ser. 295, 113-121 (2005).

36. Yorifuji, M., Harii, S., Nakamura, R. \& Fudo, M. Shift of symbiont communities in Acropora tenuis juveniles under heat stress. PeerJ 5, e4055, https://doi.org/10.7717/peerj.4055 (2017).

37. Thornhill, D. J., Lajeunesse, T. C., Kemp, D. W. \& Fitt, W. K. Multi-year, seasonal genotypic surveys of coral-algal symbioses reveal prevalent stability or post-bleaching reversion. Mar Biol 148, https://doi.org/10.1007/s00227-005-0114-2 (2006).

38. Arif, C. et al. Assessing Symbiodinium diversity in scleractinian corals via next-generation sequencing-based genotyping of the ITS2 rDNA region. Mol. Ecol. 23, 4418-4433, https://doi.org/10.1111/mec.12869 (2014).

39. Ziegler, M. et al. Biogeography and molecular diversity of coral symbionts in the genus Symbiodinium around the Arabian Peninsula. J. Biogeogr. 44, 674-686, https://doi.org/10.1111/jbi.12913 (2017).

40. Boulotte, N. M. et al. Exploring the Symbiodinium rare biosphere provides evidence for symbiont switching in reef-building corals. The ISME journal 10, https://doi.org/10.1038/ismej.2016.54 (2016).

41. Carballo-Bolaños, R., Denis, V., Huang, Y.-Y., Keshavmurthy, S. \& Chen, C. A. Temporal variation and photochemical efficiency of species in Symbiodinaceae associated with coral Leptoria phrygia (Scleractinia; Merulinidae) exposed to contrasting temperature regimes. Plos One 14, e0218801, https://doi.org/10.1371/journal.pone.0218801 (2019).

42. Jan, S. \& Chen, C.-T. A. Potential biogeochemical effects from vigorous internal tides generated in Luzon Strait: A case study at the southernmost coast of Taiwan. Journal of Geophysical Research: Oceans 114, https://doi.org/10.1029/2008JC004887 (2009).

43. Stat, M. et al. Variation in Symbiodinium ITS2 sequence assemblages among coral colonies. Plos One 6, e15854, https://doi. org/10.1371/journal.pone.0015854 (2011).

44. Rouzé, H., Lecellier, G., Pochon, X., Torda, G. \& Berteaux-Lecellier, V. Unique quantitative Symbiodiniaceae signature of coral colonies revealed through spatio-temporal survey in Moorea. Sci. Rep. 9, 7921, https://doi.org/10.1038/s41598-019-44017-5 (2019).

45. Coffroth, M. A., Poland, D. M., Petrou, E. L., Brazeau, D. A. \& Holmberg, J. C. Environmental symbiont acquisition may not be the solution to warming seas for reef-building corals. Plos One 5, e13258, https://doi.org/10.1371/journal.pone.0013258 (2010).

46. Goulet, T. L. Most corals may not change their symbionts. Mar. Ecol. Prog. Ser. 321, 1-7 (2006).

47. Little, A. F., van Oppen, M. J. H. \& Willis, B. L. Flexibility in algal endosymbioses shapes growth in reef corals. Science 304, 1492, https://doi.org/10.1126/science.1095733 (2004).

48. Reich, H. G., Robertson, D. L. \& Goodbody-Gringley, G. Do the shuffle: Changes in Symbiodinium consortia throughout juvenile coral development. (2017).

49. Buddemeier, R. W. \& Fautin, D. G. Coral bleaching as an adaptive mechanism. BioScience 43, https://doi.org/10.2307/1312064 (1993).

50. Kao, K.-W., Keshavmurthy, S., Tsao, C.-H., Wang, J.-T. \& Chen, A. C.-L. Repeated and prolonged temperature anomalies negate Symbiodiniaceae genera shuffling in the coral Platygyra verweyi (Scleractinia; Merulinidae). Zool. Stud. 57, 55 (2018).

51. Ferrara, G. et al. In. Cell. Mol. Biol. Lett. 11, 155 (2006).

52. Zhang, J., Kobert, K., Flouri, T. \& Stamatakis, A. PEAR: a fast and accurate Illumina Paired-End reAd mergeR. Bioinformatics 30, 614-620, https://doi.org/10.1093/bioinformatics/btt593 (2014).

53. Caporaso, J. G. et al. QIIME allows analysis of high-throughput community sequencing data. Nat Meth 7, 335-336, http://www. nature.com/nmeth/journal/v7/n5/suppinfo/nmeth.f.303_S1.html (2010).

54. Cunning, R., Gates, R. D. \& Edmunds, P. J. Using high-throughput sequencing of ITS2 to describe Symbiodinium metacommunities in St. John, US Virgin Islands. PeerJ 5, e3472, https://doi.org/10.7717/peerj.3472 (2017).

55. Tong, H. et al. Temperature shapes coral-algal symbiosis in the South China Sea. Scientific Reports 7, 40118, https://doi.org/10.1038/ srep40118 https://www.nature.com/articles/srep40118\#supplementary-information (2017).

\section{Author contributions}

C.A.C. designed the research. R.C.B. carried out the transplantation experiment and DNA extraction. Y.Y.H. designed PCR experiment, processed and analyzed NGS data. R.C.B and C.Y.K. performed statistical analyses. Y.Y.H. wrote the manuscript. Y.Y.H., R.C.B., S.K. and C.A.C. reviewed and edited the manuscript.

\section{Competing interests}

The authors declare no competing interests.

\section{Additional information}

Supplementary information is available for this paper at https://doi.org/10.1038/s41598-020-64749-z.

Correspondence and requests for materials should be addressed to C.A.C.

Reprints and permissions information is available at www.nature.com/reprints.

Publisher's note Springer Nature remains neutral with regard to jurisdictional claims in published maps and institutional affiliations. 
The authors declare that they have no conflict of interest or any competing interests, including financial and non-financial.

(c) Open Access This article is licensed under a Creative Commons Attribution 4.0 International License, which permits use, sharing, adaptation, distribution and reproduction in any medium or format, as long as you give appropriate credit to the original author(s) and the source, provide a link to the Creative Commons license, and indicate if changes were made. The images or other third party material in this article are included in the article's Creative Commons license, unless indicated otherwise in a credit line to the material. If material is not included in the article's Creative Commons license and your intended use is not permitted by statutory regulation or exceeds the permitted use, you will need to obtain permission directly from the copyright holder. To view a copy of this license, visit http://creativecommons.org/licenses/by/4.0/.

(c) The Author(s) 2020 